\title{
Potential for Peritoneal Metastasis after Gastric Perforation Induced by Endoscopic Submucosal Dissection of Early Gastric Cancer
}

\author{
Bong Eun Lee \\ Department of Internal Medicine, Pusan National University School of Medicine, and Biomedical Research Institute, Pusan National University \\ Hospital, Busan, Korea
}

See "Long-term Clinical Outcomes and Risk of Peritoneal Seeding after Endoscopic Submucosal Dissection for Early Gastric Cancer: A Focus on Perforation during the Procedure" by Cheal Wung Huh, et al. on page 515, Vol. 13. No. 5, 2019

Endoscopic submucosal dissection (ESD) is now a wellestablished treatment for selected cases of early gastric cancer (EGC). Although achieving en bloc resection with a higher curability rate is the major advantage of ESD over conventional endoscopic mucosal resection, it is associated with a relatively higher risk of adverse events including bleeding and perforation. The incidence of gastric ESD-induced perforation has been reported to vary from $1.2 \%$ to $8.1 \%,{ }^{1-4}$ whereas in recent, most perforations could be treated with immediate endoscopic clipping without additional surgery. ${ }^{3}$ However, there have been some concerns about the potential risk for peritoneal seeding metastasis via ESD-induced perforation., ${ }^{5,6}$

In this issue of Gut and Liver, Huh et al. ${ }^{7}$ retrospectively reviewed 556 patients who had undergone ESD for EGC between January 2002 and March 2015, and they investigated long-term clinical outcomes especially for peritoneal seeding metastasis in 34 patients who had experienced gastric perforation during ESD. Among 34 patients with perforation, macroperforation occurred in 17 patients (50\%). Twenty-seven patients were successfully treated with endoscopic clipping and six patients could recover with conservative medical treatment alone. Only one patient underwent an emergency operation due to severe panperitonitis. Final pathology revealed noncurative resection in seven patients in a perforation group, and among them, three patients received an additional gastrectomy with lymph node (LN) dissection. During the median follow-up of $51.9 \pm 27.5$ months, there was one extragastric recurrence in a perforation group. The initial pathology of this case had showed 4,000 $\mu \mathrm{m}$ submucosal invasion after an emergency wedge resection, however he refused to receive an additional curative surgery including LN dissection. Two years later, cancer recurred as massive LN metastasis in retroperitoneum and neck with brain metastasis. This patient was at high risk for perigastric LN metastasis according to the presumptive evidence of deep submucosal invasion, therefore it is thought to be reasonable to explain the poor outcome caused by initial cancer status rather than ESD-induced perforation. Finally, there was no case with peritoneal seeding metastasis in a perforation group and the cumulative survival rate was not affected by the presence of ESD-induced perforation. According to their data, the authors concluded that ESD-induced perforation might not lead to worse clinical outcomes including peritoneal seeding metastasis.

There have been several reports regarding the same issue. In one retrospective study analyzing 90 EGC patients who had suffered from gastric endoscopic resection-induced perforation, there was no case with peritoneal dissemination during the mean follow-up of 53.6 months. ${ }^{5}$ However, in recent, a retrospective study by Hirao et al. ${ }^{6}$ revealed two patients with peritoneal seeding metastasis in a total of 22 patients with ESD-induced perforation. Of these two patients, one underwent emergency surgery for acute peritonitis after ESD and he died of peritoneal and hepatic metastasis about 4.5 years later. His ESD pathology was a $9 \mathrm{~mm}$ sized intramucosal differentiated adenocarcinoma which had been en bloc resected with negative margin. The other patient showed an ESD pathologic result of a submucosal cancer invasion with positive vertical margin, and the peritoneal washing sample during additional gastrectomy revealed positive for malignancy. Therefore, the authors sug-

\footnotetext{
Correspondence to: Bong Eun Lee

Department of Internal Medicine, Pusan National University School of Medicine, and Biomedical Research Institute, Pusan National University Hospital, 179 Gudeok-ro, Seo-gu, Busan 49241, Korea

Tel: +82-51-240-7869, Fax: +82-51-244-8180, E-mail: bongsul@daum.net

pISSN 1976-2283 eISSN 2005-1212 https://doi.org/10.5009/gnl19279

(a) This is an Open Access article distributed under the terms of the Creative Commons Attribution Non-Commercial License (http://creativecommons.org/licenses/by-nc/4.0) which permits unrestricted non-commercial use, distribution, and reproduction in any medium, provided the original work is properly cited.
} 
gested a possibility of incidental peritoneal cancer cell seeding via ESD-induced perforation. And aside from gastric ESD, peritoneal seeding after fine-needle aspiration biopsy or injection therapy for cancer has been reported, as well as port-site seeding after laparoscopic surgery. ${ }^{5}$ Furthermore, surgery-induced peritoneal seeding even in cases with EGC was also proposed via the exposure of cancer cells to abdominal cavity during a curative surgery. ${ }^{8,9}$ In recent, the potential risk for peritoneal cancer cell seeding in endoscopic full-thickness resection for EGC was also prospectively assessed by investigating the ability of cancer cells to be detached by touching the tumor surface. ${ }^{10}$

The mechanism of peritoneal seeding metastasis remains unclear. In general, peritoneal metastasis is considered to occur by free cancer cells exfoliated from tumors invading the serosal layer. ${ }^{8}$ However, spilling over of a small amount of free cancer cells during surgery or ESD-induced perforation might be the cause of peritoneal seeding in EGC cases. Spillage of gastric contents where tumor cells could be floating or direct contact of the exposed tumor surface with the peritoneum or surgical instrument are possible routes of cancer cell transplantation. ${ }^{10}$ Then another critical concern is whether the free cancer cells are viable and have a tumorigenic potential. ${ }^{8}$ Although this needs more future studies, one in vitro study proved a tumorigenic potential of free cancer cells, and the possibility was supposed that surgery-induced local and systemic inflammatory/immunologic changes or cancer stem cells could make free cancer cells establish peritoneal metastasis. ${ }^{8}$ Meanwhile, Yoshida et al. ${ }^{9}$ suggested an alternative route to peritoneal metastasis through indirect pathway via lymphatics.

In summary, there is no surety whether the ESD-induced perforation can lead to peritoneal seeding metastasis. However, some studies have suggested the potential risk and presented the possible routes for peritoneal metastasis. Although peritoneal metastasis related with ESD-induced perforation is too rare and almost all reported cases were noncurative conditions with deep submucosal invasion or lymphatic invasion, we should not overlook the case of an intramucosal differentiated adenocarcinoma which achieved a curative resection. We have to further consider the publication bias and understand the different study outcomes come from different study population. In conclusion, we should aware of the potential risk of tumor cell dissemination by ESD-induced perforation despite its rarity. In current status, endoscopists always try to select appropriate patients for gastric curative ESD and to build solid basic endoscopic therapeutic skills to prevent perforation. However, once a perforation occurred, the patient should be cautiously followed up for the possibility of peritoneal metastasis especially for patients who experienced emergency operation or noncurative cases who re- fused to receive an additional surgery.

\section{CONFLICTS OF INTEREST}

No potential conflict of interest relevant to this article was reported.

\section{ORCID}

Bong Eun Lee https://orcid.org/0000-0003-2734-2134

\section{REFERENCES}

1. Imagawa A, Okada H, Kawahara Y, et al. Endoscopic submucosal dissection for early gastric cancer: results and degrees of technical difficulty as well as success. Endoscopy 2006;38:987-990.

2. Oda I, Saito D, Tada M, et al. A multicenter retrospective study of endoscopic resection for early gastric cancer. Gastric Cancer 2006;9:262-270.

3. Minami S, Gotoda T, Ono H, Oda I, Hamanaka H. Complete endoscopic closure of gastric perforation induced by endoscopic resection of early gastric cancer using endoclips can prevent surgery (with video). Gastrointest Endosc 2006;63:596-601.

4. Chung IK, Lee JH, Lee SH, et al. Therapeutic outcomes in 1000 cases of endoscopic submucosal dissection for early gastric neoplasms: Korean ESD Study Group multicenter study. Gastrointest Endosc 2009;69:1228-1235

5. Ikehara H, Gotoda T, Ono H, Oda I, Saito D. Gastric perforation during endoscopic resection for gastric carcinoma and the risk of peritoneal dissemination. Br J Surg 2007;94:992-995.

6. Hirao M, Yamada T, Michida T, et al. Peritoneal seeding after gastric perforation during endoscopic submucosal dissection for gastric cancer. Dig Surg 2018;35:457-460.

7. Huh CW, Kim GJ, Kim BW, Seo M, Kim JS. Long-term clinical outcomes and risk of peritoneal seeding after endoscopic submucosal dissection for early gastric cancer: a focus on perforation during the procedure. Gut Liver 2019;13:515-521.

8. Takebayashi K, Murata S, Yamamoto H, et al. Surgery-induced peritoneal cancer cells in patients who have undergone curative gastrectomy for gastric cancer. Ann Surg Oncol 2014;21:19911997.

9. Yoshida M, Sugino T, Kusafuka K, et al. Peritoneal dissemination in early gastric cancer: importance of the lymphatic route. Virchows Arch 2016;469:155-161.

10. Goto 0, Shimoda M, Sasaki M, et al. Potential for peritoneal cancer cell seeding in endoscopic full-thickness resection for early gastric cancer. Gastrointest Endosc 2018;87:450-456. 